\title{
Spatial variations in snow cover and seasonally frozen ground over northern China and Mongolia, 1988-2010
}

\author{
Lijian Han $^{\text {a,b,* }}$, Atsushi Tsunekawa ${ }^{\text {b }}$, Mitsuru Tsubo ${ }^{\text {b }}$, Chunyang He ${ }^{\text {c,d }}$, Miaogen Shen ${ }^{\text {e,* }}$ \\ a State Key Laboratory of Urban and Regional Ecology, Research Center for Eco-Environmental Sciences, Chinese Academy of Sciences, Beijing 100085, China \\ b Arid Land Research Center, Tottori University, 1390 Hamasaka, Tottori 680-0001, Japan \\ c State Key Laboratory of Earth Surface Processes and Resource Ecology, Beijing Normal University, Beijing 100875, China \\ d College of Resources Science and Technology, Beijing Normal University, Beijing 100875, China \\ e Institute of Tibetan Plateau Research, Chinese Academy of Sciences, Beijing 100101, China
}

\section{A R T I C L E I N F O}

\section{Article history:}

Received 29 August 2012

Received in revised form 26 December 2013

Accepted 12 February 2014

Available online 26 February 2014

\section{Keywords:}

passive microwave remote sensing

climatic warming

algorithm application

remote sensing of frozen ground and snow

\begin{abstract}
A B S T R A C T
This study investigates the spatiotemporal variability of snow cover and seasonally frozen ground in northern China and Mongolia during 1988-2010 with passive microwave remote sensing records. We used the Goodison snow algorithm, adapted by introducing an additional soil freeze/thaw indicator to improve its efficiency in mountainous areas, and soil freeze-thaw algorithm to estimate snow cover onset, duration, ablation and, for the first time, interval between snow cover ablation and thawing of seasonally frozen ground. Snow cover onset, duration, and ablation tended to vary systematically from high to low latitudes, and to trend toward early/long/late in elevated areas. The ablation-thawing interval varied from low to high latitudes/elevations, and from dry to relatively humid areas, being shorter $(<2$ weeks) in the north and elevated areas but longer in some cold-dry and plain-mountain adjacent regions. During 1988-2010, snow cover showed a later/earlier trend of the onset/ablation on the western Tibetan Plateau and a belt from northeast China to central Mongolia, with trends being stronger in spring than in autumn. The time of snow cover ablation was negatively correlated with maximum temperature in the northern study area, indicating that temperature mainly advanced snow melting in spring. However, no significant relationship between temperature and the interval was observed, suggesting that other unknown factors impact the interval. Furthermore, in the north and on Mt. Changbai the interval changed by $<2$ weeks, whereas changes were larger in cold-dry and plain-mountain transitional areas, indicating changes of Earth surface systems in those areas.
\end{abstract}

(c) 2014 Elsevier B.V. All rights reserved.

\section{Introduction}

Snow cover and seasonally frozen ground in the springtime are important hydrologic and climatic variables because of their effects on water supplies, energy exchanges, and climate-cryosphere interactions in the atmospheric boundary layer (Brown, 2000; Zhang et al., 2004). Snow cover can directly impact radiative and thermal energy budgets and the thermal condition of soil, and it indirectly impacts atmospheric circulation, hydrological processes, and ecosystem dynamics (McCabe and Wolock, 2010). Many researchers have reported that the area of snow cover has decreased significantly in the Northern Hemisphere and is negatively correlated with winter temperatures (Dye, 2002). Although previous studies have directed less attention to frozen ground than to snow cover effects, Smith et al. (2004) proposed that shifts in the timing of freeze/thaw may have important implications for ecosystem carbon fluxes in high northern latitudes; and Kimball et al.

\footnotetext{
* Corresponding authors. Tel.: +861348868 8543 (L. Han), + 8613663092403 (M. Shen).

E-mail addresses: world.han@gmail.com (L. Han), shen.miaogen@gmail.com (M. Shen).
}

(2006) found that the timing of the springtime thaw and associated onset of the growing season have a major impact on photosynthetic biomass and vegetation productivity in boreal and arctic biomes.

Understanding the duration and temporal variability of snow cover and of the following period of frozen ground in the springtime may enhance the current understanding of changes in terrestrial ecological systems (Shen et al., 2011). Accurate snow cover and frozen ground information over a large area during long time periods has been done from hemispherical to regional scales (Brown et al., 2007; Brown and Robinson, 2011). Because conventional measurement networks are sparse, remote sensing is widely applied for snow cover and frozen ground detection because such observations can be made quickly, periodically, and extensively (i.e., over a large area) (Zhang et al., 2004; Wulder et al., 2007). The space-borne passive microwave time series from the Special Sensor Microwave/Imager (SSM/I, 1987-present) provides one of the longest continuous microwave remote sensing records, which is suitable for the identification of snow cover and seasonally frozen ground with less consideration of atmospheric conditions (Koening and Forster, 2004; Han et al., 2010). Sophisticated algorithms for snow cover detection have been applied routinely at various scales (Amlien, 
2008), and a well-adapted soil freeze/thaw algorithm can be applied to SSM/I records (Zhang et al., 2004). However, little research has been carried out to examine the relationship between snow cover ablation and the thawing of seasonally frozen ground in winter-spring transitional period. Previous studies have paid less attention to snow cover and the subsequent springtime seasonally frozen ground at midlatitudes (Dye, 2002; Han et al., 2011). The objectives of this study were to examine the spatial extent and temporal trend of snow cover, the duration of the interval between snow cover ablation and the thawing of seasonally frozen ground, and the response of these phenomena to temperature changes during the recent two decades (1988-2010). Additionally, because in our previous research we have carefully examined seasonally frozen ground in our study area (Han et al., 2010, 2011), we focused here particularly on the onset, duration, and ablation of snow cover, and on the interval between snow cover ablation and the thawing of seasonally frozen ground.

\section{Materials and methods}

\subsection{Study area}

Northern China and Mongolia (Fig. 1) lie between latitudes $31^{\circ} \mathrm{N}$ and $55^{\circ} \mathrm{N}$ and longitudes $71^{\circ} \mathrm{E}$ and $136^{\circ} \mathrm{E}$ and include humid, semi-humid, semi-arid, and arid zones. We selected this region for our study because these conditions have created complex ecosystems containing components typical of many ecological and physical systems found at midlatitudes. Previous researches showed that vegetation in the region has been seriously degraded over the past several decades (Tsunekawa et al., 2005), most of the East Asia dust storms originate from the area (Zhang et al., 2008), and the recent degradation of vegetation may have upset the balance of the Earth surface system (Han et al., 2010), especially the near-surface soil dynamics, which is why we selected this area as our study area as well. A study in this area therefore could implicate global change.

\subsection{Data collection}

We used brightness temperature data from the SSM/I and the Special Sensor Microwave/Imager/Sounder in this research. Those records are available from the National Snow and Ice Data Center twice daily from both ascending and descending tracks (Armstrong et al., 2011). We used the 19 and $37 \mathrm{GHz}$ vertically polarized brightness temperature $\left(\mathrm{T}_{19 \mathrm{v}}\right.$ and $\left.\mathrm{T}_{37 \mathrm{~V}}\right)$ data from descending (morning) tracks, which are more suitable for terrestrial snow cover and frozen ground applications (Derksen et al., 2000; Han et al., 2010). Because the daily data cannot cover the whole study area, we used a time series of 7 day minimum values combination (MVC) of brightness temperatures with consideration given to the revisit period. This procedure allowed us to cover the entire study area at least once every 7 days (Han et al., 2010). Finally, we produced a time series of 7-day $M V C T_{19 v}$ and $T_{37 V}$ from 1988 to 2010 for the study area.

We applied station-based meteorological elements of the Global Summary of the Day product from the National Climate Data Center to our study: the maximum and minimum temperatures $(0.1 \mathrm{~F})$ and snow depth (0.1 in.). We used approximately 300 available stations, which are available consistently during 1988-2010, from each year in this study. Snow cover onset, ablation and duration were examined using this record, and served as ground-based measures. And in this research, when station-based records are compared to its nearby certain pixels, we used the nearest 4 pixels' averaged value.

\subsection{Data processing}

We first detected snow cover and the thawing of seasonally frozen ground by adapting the Goodison snow algorithm and soil freezethaw algorithm with SSM/I brightness temperatures. For the analysis we then estimated the interval between snow cover ablation and the thawing of seasonally frozen ground.

\subsubsection{Open water and elevated permafrost pixels}

Pixels from water-covered areas have a lower brightness temperature that may lead to algorithm failures. Pure pixel mixing analysis revealed that the $T_{19 v}$ and $T_{37 \mathrm{~V}}$ of pixels with more than $30 \%$ open water decreased by more than $20 \mathrm{~K}$ and $15 \mathrm{~K}$, respectively. As a first step we eliminated such pixels by using both the UMD Global Land Cover Classification product and Global Land Cover 2000 product as references. With respect to mid-latitude conditions, elevated permafrost is not relevant to the interval between snow cover ablation and the

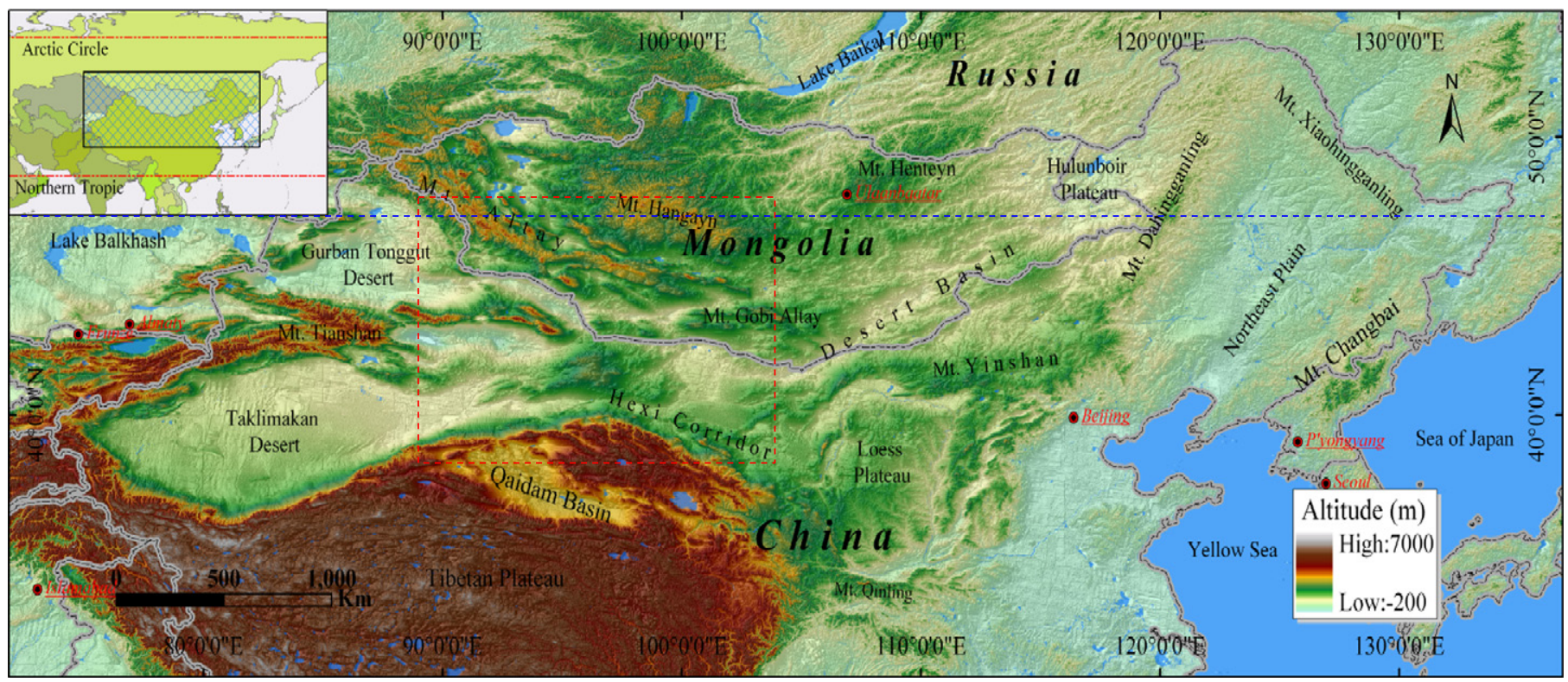

Fig. 1. Study area. The red rectangle represents the areas in Fig. 2, and the blue dashed line represents the W-E transect analysis at $47^{\circ} \mathrm{N}$ in Fig. 7 . 
thawing of seasonally frozen ground. We therefore eliminated regions with altitudes $>3000 \mathrm{~m}$ in the interval analysis by using a global digital elevation model (DEM) (available at http://eros.usgs.gov/products/ elevation).

\subsubsection{Snow cover estimation}

Many algorithms/products have been proposed/produced since the 1970s with passive microwave remote sensing records. Broad application of the Goodison snow algorithm in North America suggests that the algorithm may be applicable in other similar mid-latitude areas (e.g. northern China and Mongolia). We therefore selected it for identifying areas with or without snow cover in this work, Eq. (1), using its latest update for SSM/I brightness temperatures (e.g. Derksen et al., 2002; Goita et al., 2003; Derksen et al., 2005).

$\mathrm{SWE}=\mathrm{F}_{\mathrm{O}} \mathrm{SWE}_{\mathrm{O}}+\mathrm{F}_{\mathrm{S}} \mathrm{SWE}_{\mathrm{S}}+\mathrm{F}_{\mathrm{C}} \mathrm{SWE}_{\mathrm{C}}+\mathrm{F}_{\mathrm{D}} \mathrm{SWE}_{\mathrm{D}}$

where

$\mathrm{SWE}_{\mathrm{O}} \quad-20.7-2.59\left(\mathrm{~T}_{37 \mathrm{~V}}-\mathrm{T}_{19 \mathrm{~V}}\right)$ for open area

$\mathrm{SWE}_{\mathrm{S}} \quad-1.95-2.28\left(\mathrm{~T}_{37 \mathrm{~V}}-\mathrm{T}_{19 \mathrm{~V}}\right)$ for sparse forest

$\mathrm{SWE}_{\mathrm{C}} \quad-16.81-1.96\left(\mathrm{~T}_{37 \mathrm{~V}}-\mathrm{T}_{19 \mathrm{~V}}\right)$ for coniferous forest

$\mathrm{SWE}_{\mathrm{D}} \quad-33.50-1.97\left(\mathrm{~T}_{37 \mathrm{~V}}-\mathrm{T}_{19 \mathrm{~V}}\right)$ for deciduous forest.

SWE is snow water equivalent in the original algorithm but it is employed as a snow cover indicator in this work; SWE $>0$ indicates snow present on the surface, and SWE $\leq 0$ indicates no snow on the surface; $F_{O}, F_{S}, F_{C}$, and $F_{D}$ represent the fractions of open area, sparse forest, coniferous forest, and deciduous forest in a pixel, respectively; $S W E_{O}, S W E_{S}, S W E_{C}$, and $S W E_{D}$ are the snow water equivalents for an open area, sparse forest, coniferous forest, and deciduous forest, respectively. Those four elements are derived from the UMD Global Land Cover Classification product and Global Land Cover 2000 product.

We introduced an additional soil freeze/thaw indicator to avoid Goodison snow algorithm failure in our study area (see details of this improvement in Section 3.1). We assumed snow present on thawed ground to be rare in the study area due to the strong sublimation that occurs in the dryland; we therefore adapted a threshold of $\mathrm{T}_{37 \mathrm{~V}}$ based on the findings of a soil freeze-thaw study in the study area (Han et al., 2010). Thus, $\mathrm{T}_{37 \mathrm{~V}}>258.2 \mathrm{~K}$ indicated that no snow was present on the surface, and $\mathrm{T}_{37 \mathrm{~V}}<258.2 \mathrm{~K}$ implied that snow might be present on the surface.

Finally, snow cover was complete when $\mathrm{SWE}_{\mathrm{SSM} / \mathrm{I}}>0$ and $\mathrm{T}_{37 \mathrm{~V}}$ $<258.2 \mathrm{~K}$ over the whole study domain.

\subsubsection{Thawing of seasonally frozen ground}

Thawing of seasonally frozen ground in the springtime was detected by a soil freeze-thaw algorithm that was adapted for this area with a predefined cutoff for $\mathrm{T}_{37 \mathrm{~V}}$ of $258.2 \mathrm{~K}$ (Han et al., 2010). The algorithm required two parameters for frozen ground identification: a negative spectral gradient between $\mathrm{T}_{19 \mathrm{~V}}$ and $\mathrm{T}_{37 \mathrm{~V}}\left(\partial \mathrm{T}_{\mathrm{B}} / \partial \mathrm{f} \leq 0\right)$, and a threshold of $T_{37 \mathrm{~V}}\left(\mathrm{~T}_{37 \mathrm{~V}} \leq 258.2 \mathrm{~K}\right)$. Thawing was thus detected when either condition was no longer satisfied.

The interval between snow cover ablation and the thawing of seasonally frozen ground in the spring was then estimated as the difference between the time of thawing and time of ablation.

\subsection{Data analysis}

We calculated a weight ratio to quantify the snow fraction in the study area during the 23 years.

$$
R w_{i}=\frac{1}{23 S} \sum_{j=1}^{23} S_{i j}
$$

where $\mathrm{Rw}_{\mathrm{i}}$ represents the weight ratio in week $\mathrm{i}, \mathrm{S}$ is the total number of pixels in the study area; and $S_{i j}$ is the snow cover times $\mathrm{j}$ during the 23 years for a pixel in the $\mathrm{i}$-th week.

We calculated the trend of snow cover onset, duration, and ablation in each pixel by a least-squares approach (Eq. (3)). The statistical significance of the slopes was assessed at the $95 \%$ confidence level.

$$
T \_X=\frac{n \times \sum_{i=1}^{n}\left(i \times X_{i}\right)-\left(\sum_{i=1}^{n} i\right)\left(\sum_{i=1}^{n} X_{i}\right)}{n \times \sum_{i=1}^{n} i^{2}-\left(\sum_{i=1}^{n} i\right)^{2} .}
$$

The trend $\left(\mathrm{T} \_\mathrm{X}\right)$ of snow cover was equated to the slope of an ordinary least squares regression of year (independent variable) versus the time (dependent variable) of either the onset (T_On), duration (T_Du), or ablation (T_Ab) of snow cover.

We then calculated Pearson's correlation coefficient between anomalies of snow cover and daily maximum temperature in the winter, and between anomalies of the intervals and daily maximum temperature in the winter-spring transitional periods which is the interval of \pm 1 week. The statistical significance of these relationships was assessed at the $95 \%$ confidence level.

\section{Results}

\subsection{Validation of the algorithm for snow detection}

We compared ground-based estimates of snow cover onset, duration, and ablation with the SSM/I-based estimates. The ground-based and SSM/I-based estimates of the week of the year of the onset and ablation and number of weeks of the duration of snow cover were in agreement (total accuracy) for $84.2 \%$ ( $46.4 \pm 2.8$ for our result, while $46.9 \pm 2.6$ for ground measurement), $81.1 \%$ ( $11.5 \pm 3.8$ for our result, while $12.9 \pm 3.4$ for ground measurement), and $82.1 \%(17.1 \pm 6.1$ for our result, while $18.0 \pm 6.2$ for ground measurement), respectively (Fig. 2). Comparison of results with and without adapting the $\mathrm{T}_{37 \mathrm{~V}}$ cutoff showed an effective improvement in the estimation of snow cover duration. We selected an area with largest error without adapting the $T_{37 \mathrm{~V}}$ cutoff, the total accuracy of weeks of the duration of snow cover improving from $36.2 \%$ to $83.3 \%$ when the cutoff was used. The results were also compared with NOAA snow cover products, obtaining an $81.6 \%$ agreement. The use of the $\mathrm{T}_{37 \mathrm{~V}}$ cutoff effectively eliminated the overestimation of snow cover duration otherwise associated with the use of the Goodison snow algorithm (Fig. 3).

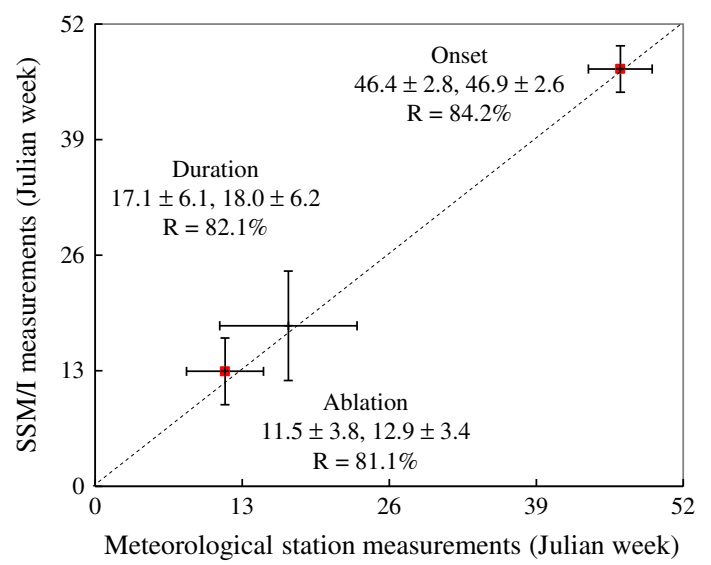

Fig. 2. Validation of snow cover onset, ablation and duration. 


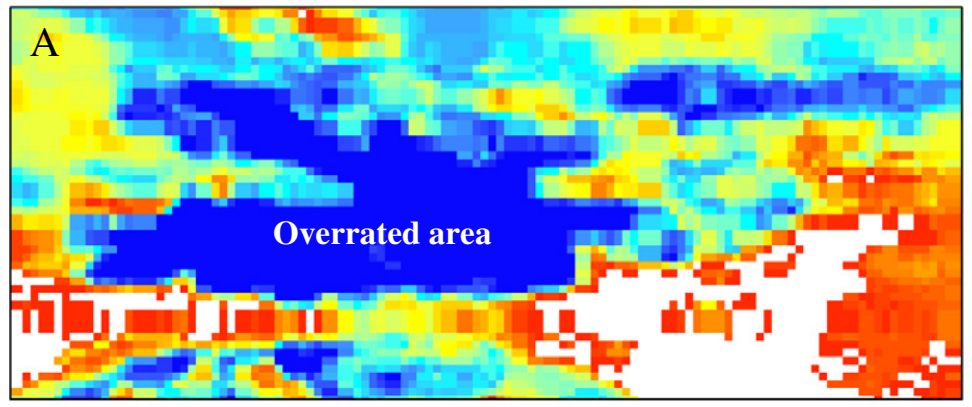

$\Lambda$

Snow

Cover

Duration

(Week)
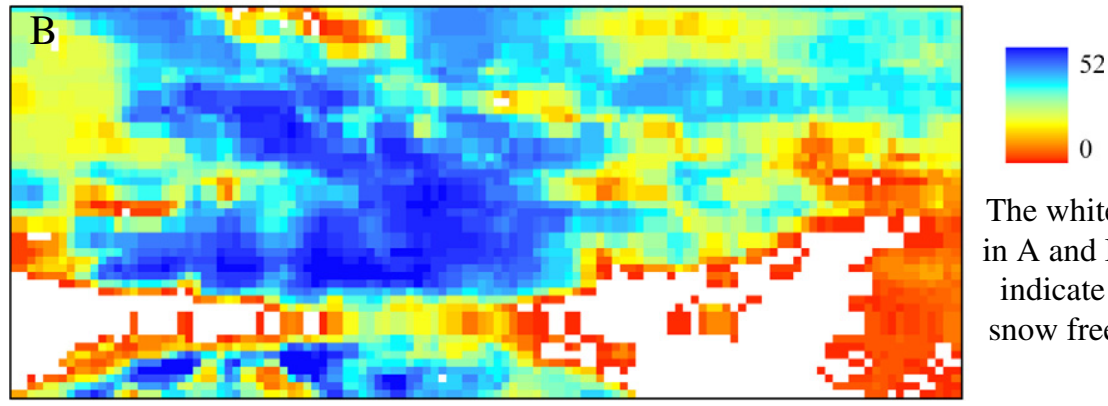

The white

in $\mathrm{A}$ and $\mathrm{B}$

indicate

snow free

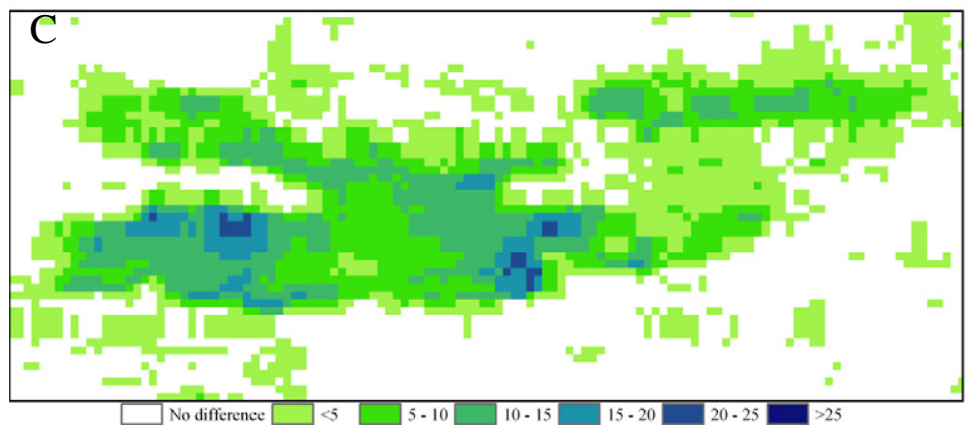

Fig. 3. Results of snow cover duration detected by Goodison snow algorithm (A) without and (B) with introduction of the cutoff of $T_{37 \mathrm{~V}}$. (C) Is the difference map between (A) and (B).

\subsection{The mean patterns of snow cover onset, duration, and ablation}

We first examined the time series of weekly snow cover quantified by the weight ratio ( $\mathrm{Rw}_{\mathrm{i}}$; Fig. 4). The maximum and minimum percentages of snow cover, $55.7 \pm 4.8 \%$ and $1.72 \pm 0.02 \%$, respectively, occurred on the 5th and 30th weeks of a year, respectively. Snow ablation occurred after the 5th week and before the 30th week, and snow ablations occurred after the 30th week and before the 5 th week of the year.

The mean spatial patterns of the onset, ablation and duration of snow cover (Fig. 5) had great regional differences. Earlier onset/later ablation/longer duration was found in two regions: west of the Tibetan Plateau (around $39^{\circ} \mathrm{N}, 72^{\circ} \mathrm{E}$ ), and in the Mt. Altay area (around $51^{\circ} \mathrm{N}$, $84^{\circ} \mathrm{E}$ ) and regions to the north of the Hexi Corridor (around $42^{\circ} \mathrm{N}$,

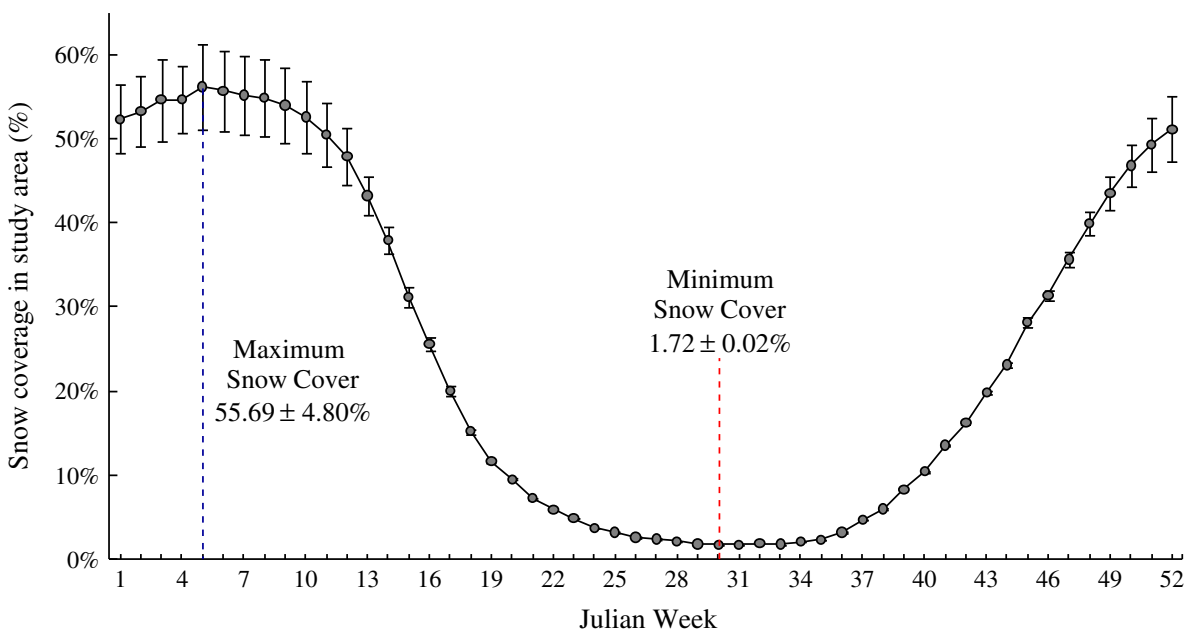

Fig. 4. The weight ratio $\left(\mathrm{Rw}_{\mathrm{i}}\right)$ of snow cover over the course of year. The dots indicate the average $\mathrm{R}_{\mathrm{wi}}$, and the vertical bars are the standard deviation of $\mathrm{R}_{\mathrm{wi}}$ during $1988-2010$. 


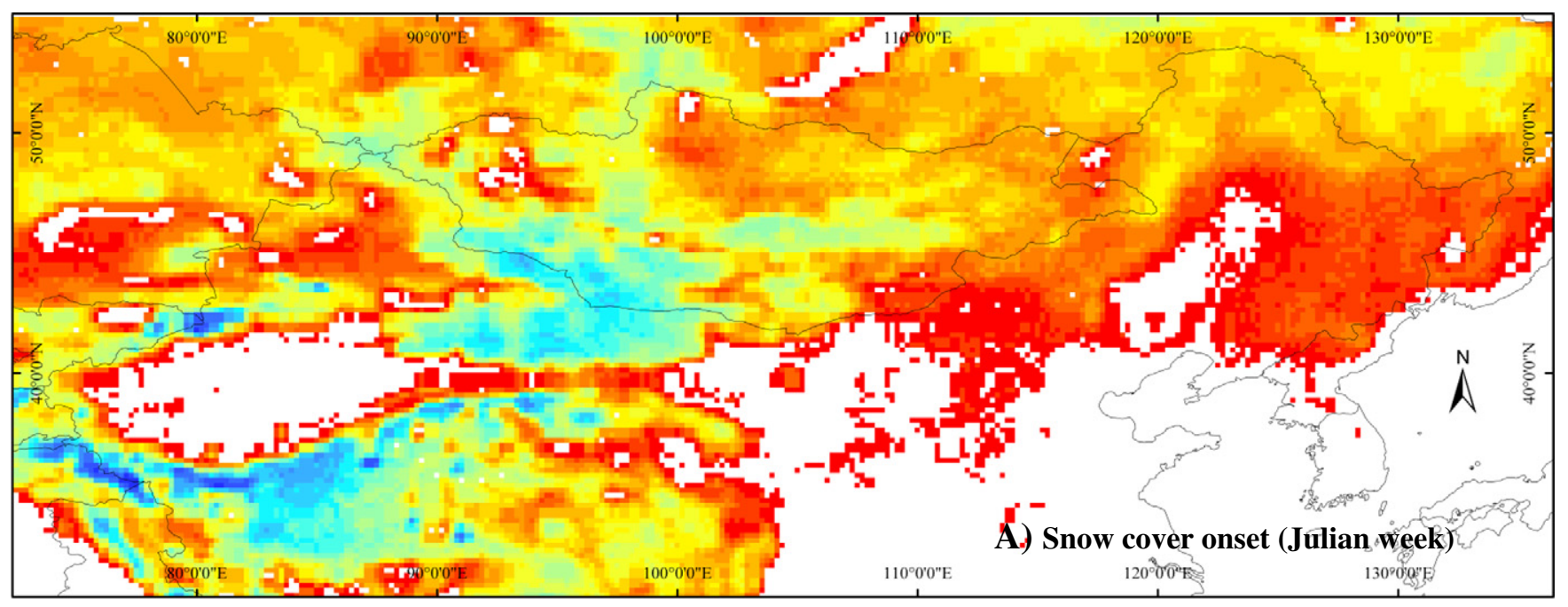

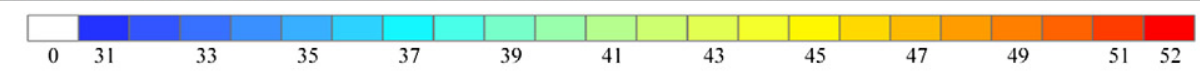
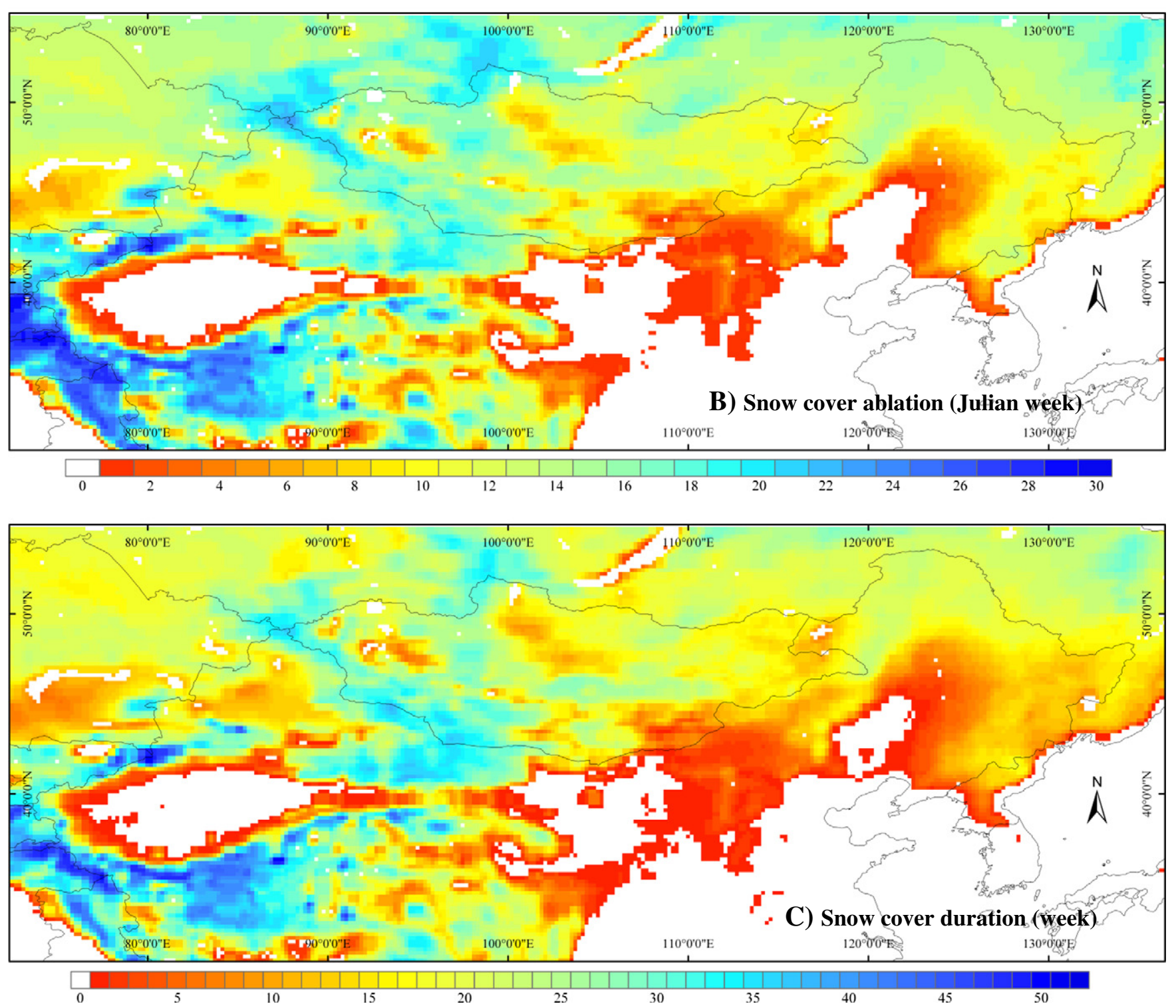

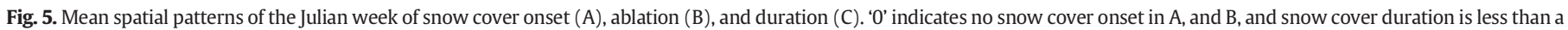
week in panel $\mathrm{C}$. 


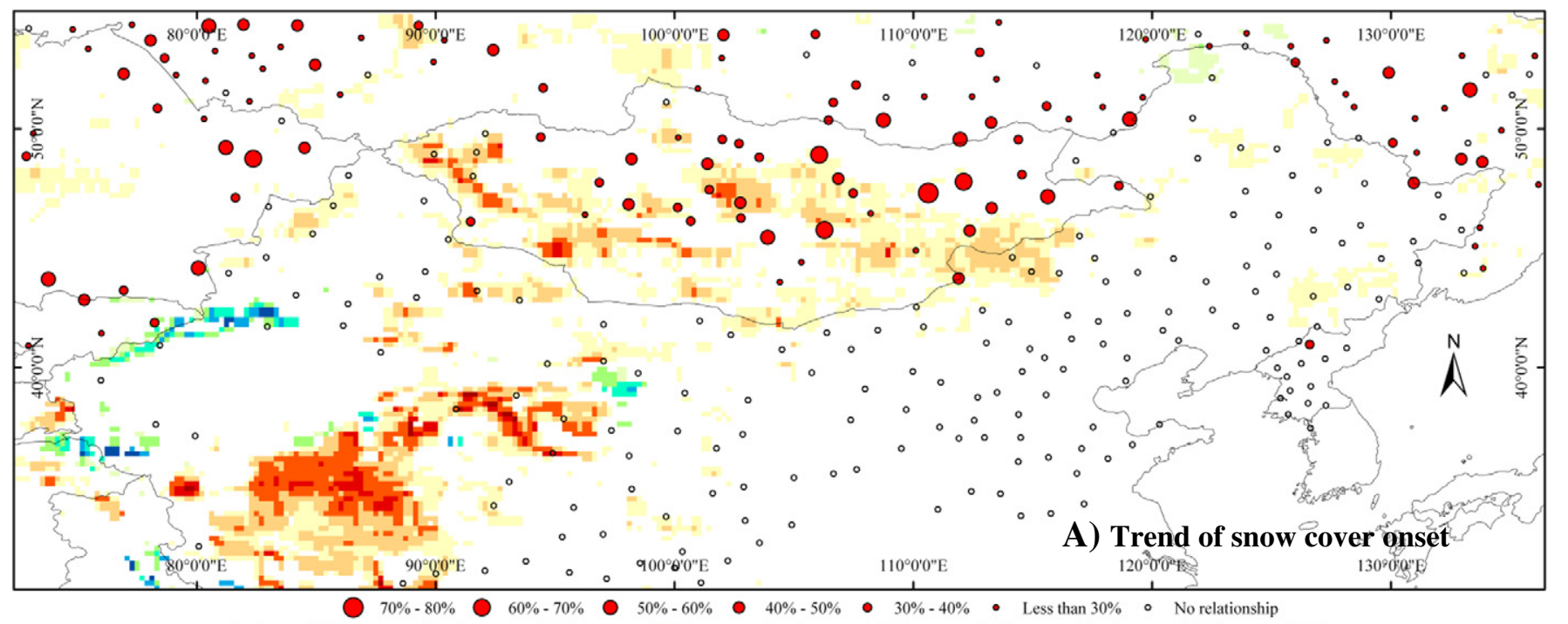

$\square<-0.50 \square-0.50 \sim-0.40 \square-0.40 \sim-0.30 \square-0.30 \sim-0.20 \square-0.20 \sim-0.10 \square-0.10 \sim 0.10 \square-0.10 \sim 0.20 \square-0.20 \sim 0.30 \square-0.30 \sim 0.40 \square-0.40 \sim 0.30 \square>0.30$

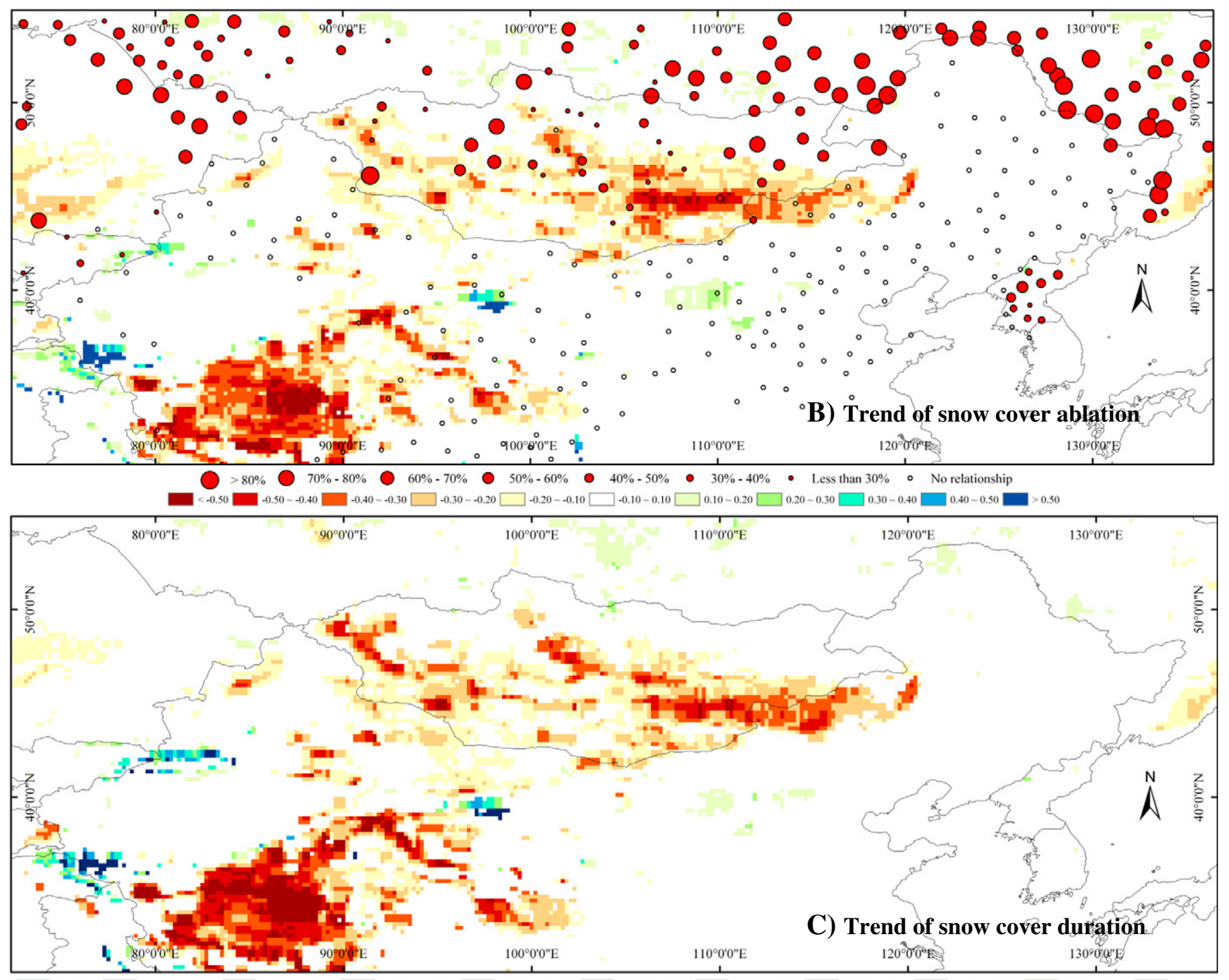

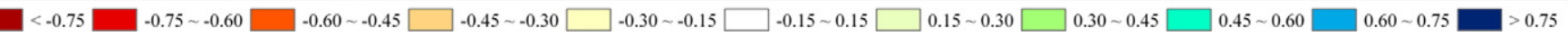

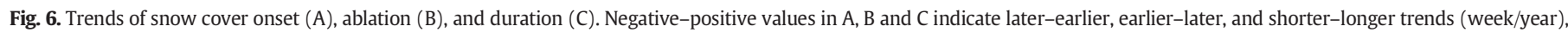

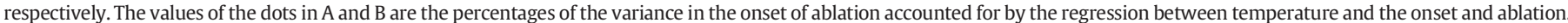
The bars indicate the trends. 
$95^{\circ} \mathrm{E}$ ). From the Tibetan Plateau, the onset/ablation/duration progressed eastward toward low-elevation areas, where no snow cover was observed. Snow cover onset/ablation/duration normally tended to progress from high to low elevations, and from high- to low-latitude areas except for the Tibetan Plateau. Areas to the south of $40^{\circ} \mathrm{N}$ were rarely covered with snow except for the Tibetan Plateau. Although snow sometimes fell during the winter, the relatively high winter temperatures caused melting within a short time. Snow likewise seldom accumulated in drylands such as the Taklimakan Desert (around $37-41^{\circ} \mathrm{N}, 75-88^{\circ} \mathrm{E}$ ), and Horqin Sandy Land (around $44^{\circ} \mathrm{N}, 122^{\circ} \mathrm{E}$ ) because of limited snowfall and intense sublimation under the cold and dry conditions.

\subsection{Trends of snow cover onset, duration, and ablation}

The trends of the onset, duration, and ablation in most of the study area during 1988-2010 were within a relatively small range (e.g. -0.1 to 0.1 weeks per year for onset and ablation; -0.15 to 0.15 weeks per year for duration), and in many cases the trends were not statistically significant $(P>0.1)$. However, there were seasonal differences and some significant $(P<0.1)$ trends, which are described below.

The onset of snow cover in autumn (Fig. 6A) tended to occur later in the year toward the end of the study period on the mid-western portion of the Tibetan Plateau as well as in Mt. Altay (around $44-51^{\circ} \mathrm{N}, 84-95^{\circ} \mathrm{E}$ ) and Qaidam Basin (around $36-39^{\circ} \mathrm{N}, 91-97^{\circ} \mathrm{E}$ ), the latter experiencing the greatest delay of onset. Small delays were also evident in a belt from northeastern China to central Mongolia. Meanwhile, trends toward earlier onsets were occasionally evident in the vicinity of Mt. Tianshan (around $42-44^{\circ} \mathrm{N}, 80-87^{\circ} \mathrm{E}$ ) and to the west and north of the Tibetan Plateau.

The spatial extension of the ablation in spring (Fig. 6B) was similar to the trend of onset in spatial extent, but both the increasing and decreasing trends were stronger. Most of the area on the Tibetan Plateau experienced a trend toward earlier ablation. The trend toward earlier ablation was especially strong on the western Tibetan Plateau, as well as along a belt from northeastern China to central Mongolia. Trends toward later ablation were evident mainly on the northwestern portion of the Tibetan Plateau and in the vicinity of Mt. Tianshan, and there were trends toward slightly later ablation to the west of Mt. Yinshan.

As the result of the opposite temporal trends of onset and ablation, the trend of snow cover duration (Fig. 6C) showed a similar spatial pattern to the trend of ablation. Most of the areas on the Tibetan Plateau showed a trend toward a shorter duration of snow cover. This pattern was especially evident on the western Tibetan Plateau, which experienced the greatest decrease of winter snow cover duration. However, the duration of snow cover increased markedly in regions along the edge of the Tibetan Plateau and in the vicinity of Mt. Tianshan. The belt from the western part of northeastern China to southern Mongolia (around $43-45^{\circ} \mathrm{N}, 109-120^{\circ} \mathrm{E}$ ) was another area of apparent decrease, the duration of snow cover tending to decrease. In contrast, in areas to the south of Mt. Changbai (around $41.5^{\circ} \mathrm{N}, 128^{\circ} \mathrm{E}$ ), to the south of Mt. Yinshan (around $40-42^{\circ} \mathrm{N}, 108-116^{\circ} \mathrm{E}$ ), to the north of northeastern China and Mongolia, and in elevated areas in the western part of the study area snow cover duration showed a slightly increasing trend.

\subsection{Relationship between snow cover and temperature}

Snow cover onset and ablation were correlated with the maximum temperature during the onset and ablation periods, which are autumn-winter and winter-spring transition periods. The correlations were negative in the northern part of the study area. Temperature had a little impact on the variation of the onset of snow cover (Fig. 6A). We found large negative correlations only in some areas in central and eastern Mongolia; correlations in the remaining areas were lower $(\mathrm{r}<50 \%)$.

The times of snow cover ablation and temperature were associated with each other in the spring (Fig. 6B). In areas to the northwest of Mt. Altay and along a belt from regions to the northeast of China to the north of Mongolia, the times of ablation were most strongly associated $(r>0.60)$ with maximum temperature, as was also the case on Mt. Changbai. But such strong relationships were not apparent in the rest of the study area.

\subsection{The mean spatial pattern and change of the interval between snow} cover ablation and the thawing of seasonally frozen ground

The mean spatial pattern of the interval varied from low to high latitudes and elevations, and from dry to relatively humid areas in the study area (Fig. 7A). The intervals were shorter (in most cases less than 2 weeks) in the north and on some elevated areas (e.g. Mt. Changbai) of the study area. We estimated the intervals to be longer in the areas surrounding the Taklimakan Desert, between Mt. Altay and Mt. Hangayn, from Mt. Gobi Altay through the Desert Basin to the Hulunboir Plateau, to the south of Mt. Yinshan and in the west of the Loess Plateau, and in the adjacent areas between the Northeast Plain and its surrounding mountains. We estimated the intervals to be longest in the Qaidam Basin, to the west of Mt. Tianshan, the Hexi Corridor, the central Desert Basin and Mt. Yinshan, and in some areas between the Northeast Plain and Mt. Changbai-Mt. Xiaohingganling.

The spatial pattern of the standard deviation of the duration of the interval during 1988-2010 (Fig. 7B) was similar to the mean spatial pattern. The interval changed in most of the areas in the north and on Mt. Changbai by less than 2 weeks. In the areas surrounding the Taklimakan Desert, between Mt. Altay and Mt. Hangayn, in the Desert Basin, in the Hulunboir Plateau, in areas to the south of Mt. Yinshan, to the west of the Loess Plateau, and in the adjacent areas between the Northeast Plain and its surrounding mountains, large changes were apparent.

A W-E transect of the standard deviations at $47^{\circ} \mathrm{N}$ showed how typical intervals varied in regions with different elevations and surface conditions (Figs. 1, 8). The intervals in high-elevation areas (e.g. Mt. Altay, Mt. Hangayn, Mt. Dahingganling, and Mt. Xiaohingganling) were shorter than those in low-elevation areas (e.g. Gurban Tonggut Desert, Northeast Hulunboir Plateau, and the Northeast Plain). Thus, elevations were highly correlated with the standard deviations of the intervals; high/low-elevation areas had small/large standard deviations. In some cases, there is a larger than 10 weeks interval happened in the dry land of northern China and Mongolia, where have very limited snow falling but ground keep freezing until the end of April or later.

\section{Discussion}

Snow cover can be detected directly by microwave remote sensing records and indirectly by setting a threshold on the estimated snow depth or water equivalent (e.g. Grody and Basist, 1996; Derksen et al., 2002, 2005). The rationale that underlies snow cover detection by microwave remote sensing is the fact that a significant decrease in the brightness temperature at high frequencies (e.g. $37 \mathrm{GHz}$ ) is accompanied by an insignificant change at lower frequencies (e.g. 18/19 GHz). The distinct difference in brightness temperatures indicates a universal algorithm for snow cover detection with microwave remote sensing records. However, various land surface conditions (e.g., forests) can change the characteristics of the response function (Goita et al., 2003). In this research, the Goodison snow algorithm performed poorly in some cold-arid regions of our study area. This poor performance was clearly evident in the regions between the Hexi Corridor and Mt. Altay-Mt. Hangayn (Fig. 1). We therefore introduced a cutoff of 258.2 $\mathrm{K}$ for $\mathrm{T}_{37 \mathrm{~V}}$ in this work to avoid failure of the Goodison snow algorithm (Figs. 2 and 3). Further research will likely be necessary to enable high- 

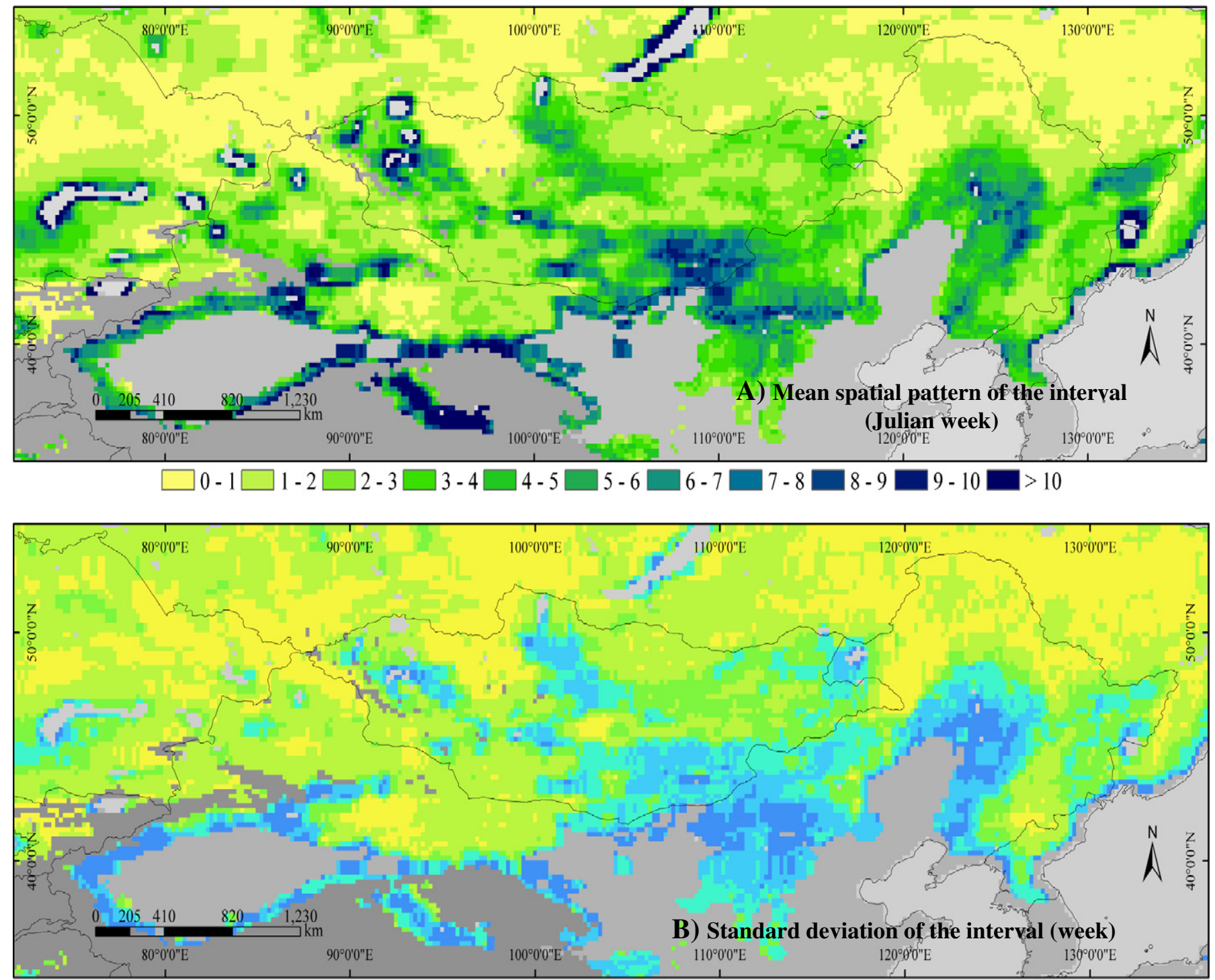

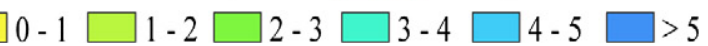

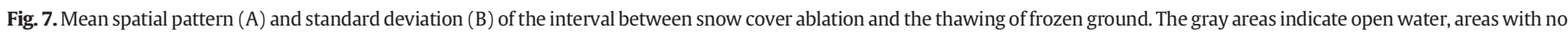
snow cover, and high-elevation $(>3000 \mathrm{~m}$ ) areas.

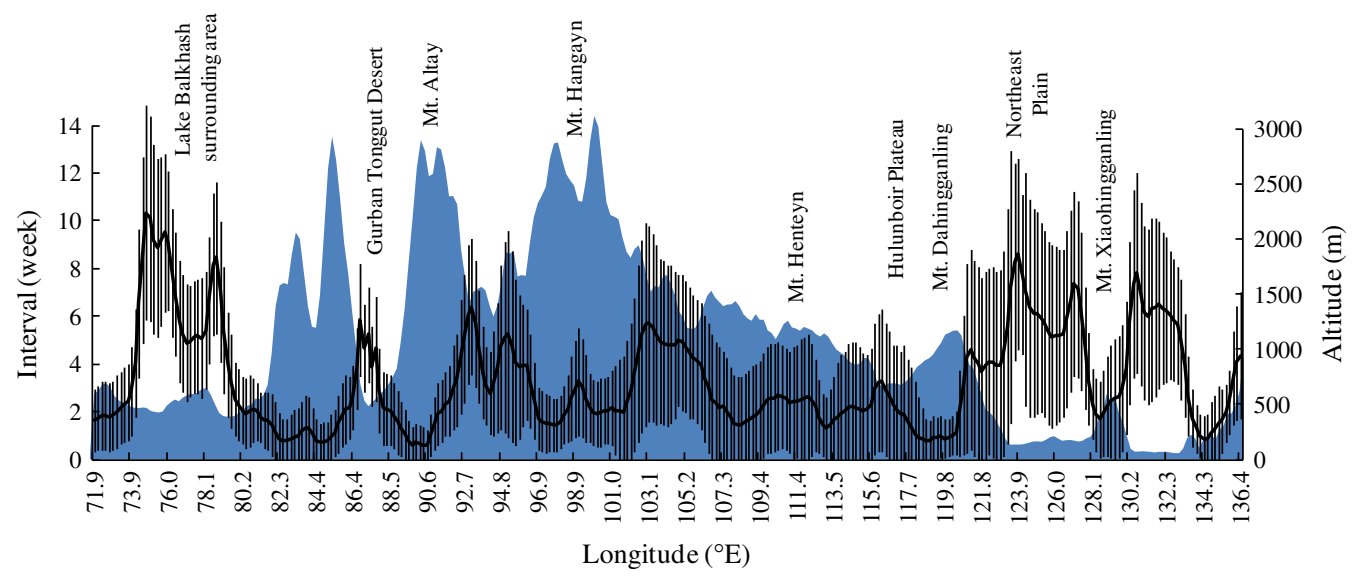

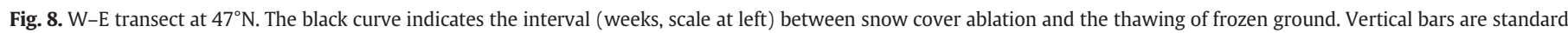
deviations. Blue shading indicates elevation (meters, scale at right). 
spatiotemporal resolution of snow cover products, particularly at midlatitudes, where near-surface regions are expected to undergo severe alterations due to climate change and human activity.

Limited full-covered and continuous daily satellite record at midlatitudes is currently available, mainly because of limitation of revisit interval for microwave remote sensing programs and atmospheric conditions for visible and near-infrared bands. Han et al. (2010) suggested a 7-day maximum/minimum value combined with SSM/I brightness temperature to be used in seasonally frozen ground studies. This statistics loses detailed information within each 7-day interval but provides an optional metric for producing standard temporal interval datasets at mid-latitudes. However, the 7-day MVC algorithm can introduce an error of \pm 1 week, which should be reduced with temporal downscale improvement in future research. Higher spatial resolution satellite records and/or spatial downscale methods are also needed because of the impact of open water on brightness temperatures. In this research, we attributed the longer intervals detected in the areas surrounding Lake Balkhash (Fig. 6B), as well as other lakes (Fig. 7), primarily to the impact of open water on brightness temperatures, an effect that caused algorithm failure even when pixels with more than $30 \%$ open water were eliminated. We also considered the time of the first snowfall to be a factor that potentially affects the onset of snow cover, because minimum temperatures at the time of the first snowfall were lower than $-10{ }^{\circ} \mathrm{C}$, which is sufficient to maintain snow on the ground after a snowfall. In additional, we utilized significance of $P<0.1$ to analyze the relationship between the snow onset/duration/ ablation, which may overdraw the trends in 20 years. Further research to validate this snow trend is highly recommended.

The durations of snow cover and seasonally frozen ground are essential inputs to the examination of climate and Earth near-surface changes during the winter-spring transitional season. Those changes have been particularly significant in the mid-latitudes (McCabe and Wolock, 2010). At mid-latitudes, North America has been a primary focus of snow cover duration studies (Brown et al., 2007; Wulder et al., 2007). Researchers have also paid special attention to western China, especially the Tibetan Plateau, but few similar studies have concerned Mongolia (Qin et al., 2006; Che et al., 2008). Han et al. (2010) reported a relatively severe change of seasonally frozen ground during the spring than during the fall over northern China and Mongolia. Thus, research that focuses on the combination of snow cover ablation and the duration of the interval between snow cover ablation and the thawing of seasonally frozen ground would lead to a better description of seasonal climatic patterns/changes. Future work on snow cover ablation, the interval between snow cover ablation and the thawing of seasonally frozen ground, and the onset of green-up will lead to a better understanding of the surface physical and ecological systems of the Earth in typical mid-latitude areas.

A noteworthy region of special importance in the study area is the Tibetan Plateau, which is mainly covered with permafrost and has a unique effect on the climate of East Asia. Large interannual variations with a small increasing trend of snow cover were evident during 1951-1997 (Qin et al., 2006). However, the change of snow mass was not statistically significant (Che et al., 2008). The time interval of our study was coincident with that of a previous satellite-based snow cover study that reported a reduction of snow cover during 1966-2001 (Rikiishi and Nakasato, 2006). The reason for the difference among those observations remains unclear.

The Earth climate has warmed over the last 100 years during two main periods: (1) 1910-1945; and (2) 1976-present. Warming during the second period has approximately doubled to that of the first period (Walther et al., 2002). Temperature is a popular indicator for assessing the state and change of the climate, and responses of climate change are therefore quantified locally/regionally on the basis of temperature anomalies. Moreover, regional climate changes are very heterogeneous temporally and spatially (Shen et al., 2012; Shen et al., 2014a). Recent warming of Northern Hemisphere land in particular is typically greater in winter/spring than in other seasons (e.g. Schwartz et al., 2006; Shen et al., 2014b). On average over Northern Hemisphere continents and in relatively cold areas of Eurasia, Brown (2000) reported a significant reduction in April snow cover extension associated with a significant spring warming, an indication that climate changes in mid-latitudes of Eurasia might be great as well. Moreover, East Asian last-freeze dates are getting earlier faster than first-leaf dates, an indication that the impact of climate warming is greater in the winter-spring than in the fallwinter transitional season at mid-latitudes (Schwartz et al., 2006). Results of the present study showed decreasing trends to be larger in the spring, with spatial differences, particularly in the belt from northeast China to central Mongolia, decreasing during the last two decades, which meets the previous results that springtime climatic change is larger than other season at the Northern Hemisphere (IPCC, 2013). Temperature, however, was not the driving force for the trend toward earlier thawing. The decrease could instead be largely attributed to the limited snowfall and intense sublimation under the cold and dry conditions that characterize this area (McKenna-Neuman, 1993). Furthermore, the stronger relationship between snow cover ablation and temperature during the spring in the north also indicated that temperature could potentially advance/delay ablation to a significant extent, the result being a reduction/increase of snow cover duration in the winter and winter-spring transitional season. For the first time we estimated the interval between snow cover ablation and the thawing of seasonally frozen ground, with the interval we supposed to be another important indicator of the winter-spring transitional season. We found, however, no significant relationship of this interval to temperature. Explanations for this result include the possibilities that (1) air temperature was not the driving force behind changes of the interval; and/or (2) the changes were less than one week (e.g. north of the study area) and were therefore undetectable in the weekly combined results.

\section{Conclusion}

In conclusion, the 7-day MVC SSM/I brightness temperature records provide an optional way to obtain estimates of the time interval associated with snow and seasonal ground conditions in the winter and winter-spring transition periods at mid-latitudes. The Goodison snow algorithm, adjusted with an additional frozen ground indicator to correctly assess snow cover information in some mountain areas, was effective in detecting snow cover on northern China and Mongolia. Snow cover duration and the interval between snow cover ablation and the thawing of seasonally frozen ground are correlated with both latitude and elevation, but the relationships are disturbed in some cold-dry areas. The trend of snow cover is stronger in spring than in autumn, and a major change of the trend of snow cover is evident in the belt from northern China to central Mongolia. In the northern study area temperature plays an important role in snow cover ablation, suggesting that the potential impact of temperature change will occur there first. The interval between snow cover ablation and the thawing of seasonally frozen ground, which this study has been the first to estimate, is clearly correlated with elevation, but its relationship to climatic parameters remains unclear.

\section{Acknowledgments}

This research was supported by the Japanese Society for Promotion of Science Core University Program and the Global Center of Excellence Program for Dryland Science of the Japanese Ministry of Education, Culture, Sports, Science and Technology. We further thank the following data providers: U.S. National Snow and Ice Data Center for DMSP SSM/ISSMIS Pathfinder Daily EASE-Grid Brightness Temperatures; U.S. National Climate Data Center for the Global Summary of the Day Product; the University of Maryland Department of Geography for the Global Land Cover Classification; Joint Research Center Global 
Environment Monitoring Unit of European Commission for the Global Land Cover 2000 product; and the United States Geological Survey for the Digital Elevation Model (DEM) product.

\section{References}

Amlien, J., 2008. Remote sensing of snow with passive microwave radiometers: a review of current algorithms. Norsk Regnesentral, Report No. 1019978-82-539-0529-7.

Armstrong, R.L., Knowles, K.W., Brodzik, M.J., Hardman, M.A., 2011. DMSP SSM/I-SSMIS Pathfinder Daily EASE-Grid Brightness Temperatures. 1988 to 2010. National Snow and Ice Data Center, Boulder, Colorado USA (Digital media).

Brown, R., 2000. Northern Hemisphere snow cover variability and change, 1915-97. J. Clim. 13, 2339-2355

Brown, R., Robinson, D., 2011. Northern Hemisphere spring snow cover variability and change over 1922-2010 including an assessment of uncertainty. Cryosphere 5, 219-229. http://dx.doi.org/10.5194/tc-5-219-2011.

Brown, R., Derksen, C., Wang, L., 2007. Assessment of spring snow cover duration variability over northern Canada from satellite datasets. Remote Sens. Environ. 71, 297-308. http://dx.doi.org/10.1016/j.rse.2006.09.035.

Che, T., Li, X., Jin, R., Armstrong, R., Zhang, T., 2008. Snow depth derived from passive microware remote-sensing data in China. Ann. Glaciol. 49, 145-154.

Derksen, C., LeDrew, E., Walker, A., Goodison, B., 2000. The influence of sensor overpass time on passive microwave retrieval of snow cover parameters. Remote Sens. Environ. 71, 297-308.

Derksen, C., Walker, A., LeDrew, E., Goodison, B., 2002. Time-series analysis of passivemicrowave-derived central North American snow water equivalent imagery. Ann. Glaciol. 34, 1-7.

Derksen, C., Walker, A., Goodison, B., 2005. Evaluation of passive microwave snow water equivalent retrievals across the boreal forest/tundra transition of western Canada. Remote Sens. Environ. 96, 315-327.

Dye, D.G., 2002. Variability and trends in the annual snow-cover cycle in Northern Hemisphere land areas, 1972-2000. Hydrol. Process. 16, 3065-3077.

Goita, K., Walker, A.E., Goodison, B.E., 2003. Algorithm development for the estimation of snow water equivalent in the boreal forest using passive microwave data. Int. J. Remote Sens. 24, 1097-1102.

Grody, N.C., Basist, A.N., 1996. Global identification of snow cover using SSM/I measurements. IEEE Trans. Geosci. Remote 34, 237-249.

Han, L., Tsunekawa, A., Tsubo, M., 2010. Monitoring near-surface soil freeze-thaw cycles in northern China and Mongolia from 1998 to 2007. Int. J. Appl. Earth Obs. 12, 375-384. http://dx.doi.org/10.1016/j.jag.2010.04.009.

Han, L., Tsunekawa, A., Tsubo, M., 2011. Radar remote sensing of springtime near-surface soil thaw events at mid-latitudes. Int. J. Remote Sens. 32, 8555-8574. http:// dx.doi.org/10.1080/01431161.2010.542203.
Intergovernmental Panel on Climate Change (IPCC), 2013. Climate Change 2013: The Physical Science Basis.

Kimball, J.S., McDonald, K.C., Zhao, M., 2006. Spring thaw and its effect on terrestria vegetation productivity in the western Arctic observed from satellite microwave and optical remote sensing. Earth Interact. 10, 21.

Koening, L.S., Forster, R.R., 2004. Evaluation of passive microwave snow water equivalent algorithms in the depth hoar-dominated snow pack of the Kuparuk River Watershed, Alaska, USA. Remote Sens. Environ. 93, 511-527. http://dx.doi.org/10.1016/ j.rse.2004.08.004.

McCabe, G.J., Wolock, D.M., 2010. Long-term variability in Northern Hemisphere snow cover and associations with warmer winters. Clim. Chang. 99, 141-153. http:// dx.doi.org/10.1007/s10584-009-9675-2.

McKenna-Neuman, C., 1993. A review of aeolian transport processes in cold environments. Prog. Phys. Geogr. 17, 137-155.

Qin, D., Liu, S., Li, P., 2006. Snow cover distribution, variability, and response to climate change in Western China. J. Clim. 19, 1820-1833.

Rikiishi, K., Nakasato, H., 2006. Height dependence of the tendency for reduction in seasonal snow cover in Himalaya and the Tibetan Plateau region, 1966-2001. Ann. Glaciol. 49, 145-154.

Schwartz, M.D., Ahas, A., Aasa, A., 2006. Onset of spring starting earlier across the Northern Hemisphere. Glob. Chang. Biol. 12, 343-351.

Shen, M., Tang, Y., Chen, J., Zhu, X., Zheng, Y., 2011. Influences of temperature and precipitation before the growing seasn on spring phenology in grasslands of the central and eastern Qinghai-Tibetan Plateau. Agricultural and Forest Meteorological 151, 1711-1722.

Shen, M., Tang, Y., Chen, J., Yang, W., 2012. Specification of thermal growing season in temperate China from 1960 to 2009. Climatic Change 114, 783-798.

Shen, M., Zhang, G., Cong, N., Wang, S., Kong, W., Piao, S., 2014a. Increasing altitudinal gradient of spring vegetaion phenology during the last decade on the Qinghai-Tibetan Plateau. Agricultural and Forest Meteorology 189-190, 71-80.

Shen, M., Tang, Y., Chen, J., Yang, X., Wang, C., Cui, X., Yang, Y., Han, L., Du, J., Li, L., Zhang, G., Cong, N., 2014b. Earlier-season vegetation has greater temperature sensitivity of spring phenology in Northern Hemisphere. PLOS ONE 9 (2), e88178.

Smith, N.V., Saatchi, S.S., Randerson, J.T., 2004. Trends in high northern latitude soil frozen and thaw cycles from 1998 to 2002. J. Geophys. Res. 109, D12101.

Walther, G., Post, E., Convey, P., et al., 2002. Ecological responses to recent climate change. Nature 416, 389-395.

Wulder, M., Nelson, T., Derksen, C., Seemann, D., 2007. Snow cover variability across central Canada (1978-2002) derived from satellite passive microwave data. Clim. Chang. 82, 113-130. http://dx.doi.org/10.1007/s10584-00609148-9.

Zhang, T., Barry, R.G., Armstrong, R.L., 2004. Application of satellite remote sensing techniques to frozen ground studies. Polar Geogr. 28, 163-196. 